\title{
Clinical evaluation of postoperative sensitivity using self-etching adhesives containing glutaraldehyde
}

\begin{abstract}
Armando Brito Chermont ${ }^{(a)}$ Karina Kato Carneiro ${ }^{(b)}$ Marcelo Figueiredo Lobato(b) Sissy Maria Mendes Machado ${ }^{(b)}$ Mário Honorato Silva e Souza Junior ${ }^{(c)}$
\end{abstract}

(a) MSc, Associate Professor; (c)PhD, Associate Professor - Department of Restorative Dentistry, School of Dentistry, Federal University of Pará, Belém, Pará, Brazil.

(b) MSc Students, School of Dentistry, Federal University of Pará, Belém, Pará, Brazil.

Corresponding author:

Mário Honorato Silva e Souza Junior

Tv. D. Romualdo de Seixas, 156, apt. 501

Belém - PA - Brazil

CEP: 66050-110

E-mail:mario-honorato@hotmail.com

Received for publication on Mar 30, 2010 Accepted for publication on May 14, 2010

\begin{abstract}
The present clinical study aimed to assess the postoperative sensitivity (POS) after 48 hours and seven days in occlusal restorations bonded with three different adhesive systems, two of them containing glutaraldehyde. The restorative procedures were performed using the three-step etch-and-rinse Adper SBMP-Plus adhesive (SBMP), the twostep etch-and-rinse Gluma Comfort One Bond + Desensitizer adhesive $(\mathrm{GC}+\mathrm{D})$ and the all-in-one self-etching/priming I Bond (IB) adhesive, which also has glutaraldehyde in its formula. All cavities were restored with Filtek Supreme nanoparticle composite resin. After 48 hours and seven days the patients were recalled and the postoperative sensitivity evaluated. The data analyzed by non-parametric Friedman test showed no significant differences in POS among the three tested groups after 48 hours and seven days.
\end{abstract}

Descriptors: Adhesives; Dentin sensitivity; Clinical trial.

\section{Introduction}

In the hydrodynamic theor $y^{1}$, a stimulus applied to dentin increases the flow of tubular fluid that in its turn activates the nerves situated at the inner ends of the tubules or in the outer layers of the pulp. It has been common to have postoperative sensitivity (POS) related to adhesive restorations. ${ }^{2,3,4,5,6}$ POS is associated with an increase in dentin permeability ${ }^{6}$ and with the residual stresses from shrinkage in adhesive/composite resin restorations that may cause debonding and/or cusp deformation. $., 8,9,10,11$ Etch-and-rinse systems increase dentin permeability and hydraulic conductance. ${ }^{6}$ Two-step etch-and-rinse systems containing high percentages of hydrophilic monomers are found to exhibit high degrees of permeability after polymerization, that may increase nanoleakage expression ${ }^{12}$ and allow water passage through a hybrid layer. ${ }^{13,14}$ Some systems use a desensitizer, as glutaraldehyde, associated with monomers. Three-step adhesives employ a hydrophobic coat to prevent the water flow through the adhesive interface. ${ }^{8,15}$ An alternative approach is based on the use of nonrinse acidic monomers that simultaneously etch and prime enamel and dentin, the so called self-etching/priming adhesives. They are believed to be less technique sensitive due to the reduced number of steps that may prevent POS. ${ }^{2,3,8,9,15,16}$ Recently, all-in-one (1 bottle) adhesives became available. Some of them are very attractive to dental practitioners and also may have a glutaraldehyde added to its formula as a desensitizer. 
Considering that all systems mentioned have a mechanism that somehow intends to prevent POS, the purpose of this clinical study is to test the null hypothesis that adhesives containing glutaraldehyde perform equally well to conventional threestep etch-and-rinse systems regarding POS after 48 hours and seven days.

\section{Material and Methods}

Patients ranging in age from 18 to 50 years were recruited for this study. They were all female and needed at least three class I restorations in molars or premolars. The teeth to be restored had to present opposing and adjacent contacts, and not exhibit primary or secondary trauma, excessive clenching, bruxism or TMJ disorders. No previous sensitivity, low caries risk and good periodontal health were also necessary.

Before participating in this clinical research the patients read and signed the consent form, which explained the nature of the study and the technical procedures that would be performed during all phases of the study. The consent form was reviewed and approved by the Bioethics Committee at the University of Para (Brazil) under number 016/2005, in accordance with the declaration of Helsinki.

Class I cavities were cut and the faciolingual average width was between $1 / 3$ and $2 / 3$ of the cusp tips distance.

\section{Restorative procedures}

The treatments were assigned alternately among patients, tooth type (molars and premolars) and tooth initial condition (decayed or previously re- stored). Sixty teeth, molars (34) and premolars (26), were prepared and restored (one by appointment) using incremental placement technique. For all three groups, the treated cavities were obliquely layered with A3B Filtek Supreme nanoparticles composite resin (3M/ESPE, St. Paul, MN USA). Each 2 mmthick increment was cured for 20 seconds with a quartz tungsten halogen lamp (Ultralux - Dabi Atlante- Ribeirão Preto, São Paulo, Brazil) with an output of $400 \mathrm{~mW} / \mathrm{cm}^{2}$. Table 1 depicts the main components of the materials employed in the study.

At the end of the restorative procedures the distribution regarding the initial tooth condition was 44 previously restored $(73.3 \%)$ and 16 decayed (26.6\%).

\section{Postoperative sensitivity evaluation (48 hours- $\mathrm{T}_{1}$ and seven days- $\mathrm{T}_{2}$ )}

This part of the study was blindly conducted after 48 hours and seven days by one previously trained examiner who did not participate in the restorative procedures and was unable to detect the system used.

\section{Report from patient}

At both evaluation periods patients were requested to describe any postoperative discomfort and the data were scored according to the following criteria:

- $\mathbf{0}$ (zero) - no discomfort;

- 1 (one) - mild discomfort during drinking and/ or eating, but the patient did not modify the masticatory routine;

- 2 (two) - strong discomfort (pain) during drink-

Table 1 - Materials used in the study.

\begin{tabular}{|c|c|c|c|}
\hline Groups & Materials & Composition & Manufacturer \\
\hline 1 & Adper SBMP-P & $\begin{array}{l}\text { Etchant- 35\% phosphoric acid } \\
\text { Primer- HEMA, polyakenoic acid polymer, water / Adhesive- Bis- } \\
\text { GMA, HEMA, tertiary amines, photo-initiators }\end{array}$ & $\begin{array}{l}\text { 3M/ESPE } \\
\text { St. Paul, MN, USA }\end{array}$ \\
\hline 2 & $\begin{array}{l}\text { Gluma Comfort One } \\
\text { Bond + Desensitizer }\end{array}$ & $\begin{array}{c}\text { Etchant- 35\% phosphoric acid / Adhesive- UDMA, HEMA, } 4 \text { META, } \\
\text { Glutaraldehyde, ethanol, water, photo-initiators, stabilizers }\end{array}$ & $\begin{array}{l}\text { Heraeus Kulzer } \\
\text { Hanau, Hesse, Germany }\end{array}$ \\
\hline 3 & I Bond & $\begin{array}{l}\text { UDMA, } 4 \text { META, Glutaraldehyde, acetone,water, } \\
\text { photo-initiators, stabilizers }\end{array}$ & $\begin{array}{l}\text { Heraeus, Kulzer } \\
\text { Hanau, Hesse, Germany }\end{array}$ \\
\hline Composite & Filtek Supreme & $\begin{array}{c}\text { Bis-GMA, UDMA, Bis-EMA, TEG-DMA, silicon-zircon } \\
\text { nanoparticles and nanoaglomerated }\end{array}$ & $\begin{array}{c}\text { 3M/ESPE } \\
\text { St. Paul, MN, USA }\end{array}$ \\
\hline
\end{tabular}


ing and/or eating, and the patient modified the masticatory routine;

- 3 (three) - Unbearable pain, the restoration needed to be removed immediately.

\section{Tests with stimuli application \\ Cold}

A cold tetrafluorethane spray (Endo-Ice-Hygienic, Akron, OH, USA) was applied with a cotton pellet on the middle of the buccal surface for up to 5 seconds.

\section{Pressure}

A $2 \mathrm{~mm}$ silicone disc was placed on the restored tooth and the patient was instructed to bite until all occlusal contacts were achieved. This pressure was sustained for up to 5 seconds.

During the tests the patients were asked to register the discomfort using a visual analogue scale (VAS) according to the following parameters:

- 0 - no discomfort;

1 to 3 - light discomfort;

- 4 to 6 - mild discomfort;

- 7 to 9 - intense discomfort (pain);

- 10 - Unbearable discomfort (excruciating pain).

The Friedman non-parametric analysis was applied to the results $(\mathrm{p}<0.05)$ in all periods: $\mathrm{T}_{0}$ (preoperatory sensitivity), $\mathrm{T}_{1}$ (48 hours), $\mathrm{T}_{2}$ (seven days) and $\mathrm{T}_{3}$ (33 months).

\section{Results \\ Report from patient}

It was assumed that the preoperatory sensitivity was zero $\left(\mathrm{T}_{0}\right)$. At $\mathrm{T}_{1}$ only two teeth $(10 \%)$ restored with SBMP/Filtek Supreme presented postoperative sensitivity (score 1) according to the patient's report. In these cases mild discomfort during drinking and/ or eating was present, but the patient did not modify the habitual chewing routine. At $\mathrm{T}_{2}$ no teeth were sensitive.

No significant differences $(\mathrm{p}=0.96)$ were detected among $\mathrm{T}_{0}, \mathrm{~T}_{1}$ and $\mathrm{T}_{2}$.

\section{Tests with stimuli application}

Some non-involved teeth were first tested with cold and pressure stimuli to inform the patient of his or her normal sensitivity levels. Next, the stimuli were applied to the restored teeth and the patient instructed to classify the sensitivity, according to VAS, beyond this point. Therefore, the normal sensitivity should be considered as 0 (zero). When the cold test was applied at $T_{1}$, the results indicated, according to the visual analogue scale $(0-10)$, two teeth $(10 \%)$ with an increase in POS, score 2 and 3, respectively (light discomfort). The pressure test also detected two sensitive teeth (10\%), score 2 and 3 (light discomfort), both restored with SBMP/Filtek Supreme. The remaining teeth tested did not show any changes in sensitivity. At $T_{2}$, no POS was detected after cold and pressure tests. No significant differences in POS $(p>0.05)$ were detected among the groups at $\mathrm{T}_{0}, \mathrm{~T}_{1}$ and $\mathrm{T}_{2}$.

\section{Long-term partial evaluation}

Our initial objective was to assess the POS after 48 hours and seven days, to focus on the immediate effect of glutaraldehyde. However, after 33 months $\left(\mathrm{T}_{3}\right)$ we were contacted by six patients complaining of tooth sensitivity. Therefore, it was possible to evaluate the twenty one teeth at $\mathrm{T}_{0}, \mathrm{~T}_{1}, \mathrm{~T}_{2}$ and $\mathrm{T}_{3}$. One patient had six restorations (two with each system) and five patients presented three restorations (one with each system). Table 2 depicts the results from patient's report and Table 3 the results obtained after cold and pressure tests.

After 33 months the results were different from those detected at $\mathrm{T}_{0}, \mathrm{~T}_{1}$ and $\mathrm{T}_{2}$. Unfortunately, the sample had a significant drop, which may have compromised the interpretation of the analysis. Even so, the test was applied comparing the results at $\mathrm{T}_{0}, \mathrm{~T}_{1}$, $\mathrm{T}_{2}$ and $\mathrm{T}_{3}$, obtained only from the 21 restored teeth.

The results at $\mathrm{T}_{0}, \mathrm{~T}_{1}, \mathrm{~T}_{2}$ and $\mathrm{T}_{3}$ detected significant differences $(p=0.0261)$ in POS according to the patient's report at $T_{3}$ for the teeth restored with IB/Filtek Supreme. These 21 teeth were also evaluated after cold and pressure stimuli (Table 3 ) and the

Table 2 - Results from patient report after 33 months.

\begin{tabular}{c|c|c|c}
\hline Adhesive & G1-SBMP-P & G2- GC+D & G3- IB \\
\hline$T_{3}$ & $1(1) 0(6)$ & $1(1) 0(6)$ & $2(4) 1(2) 0(1)$ \\
\hline
\end{tabular}

Score* (number of teeth). ${ }^{*} 0-3$ according to determined parameters. 


\begin{tabular}{|c|c|c|c|c|c|c|c|}
\hline \multirow{7}{*}{$\begin{array}{l}\text { Table } 3 \text { - Results from } \\
\text { cold and pressure tests } \\
\text { applied at } T_{0}, T_{1}, T_{2} \text {, and } T_{3} \\
\text { for the twenty-one teeth. }\end{array}$} & \multirow{7}{*}{$\begin{array}{c}\mathrm{T}_{3} \\
\text { Score* } \\
\text { (number of } \\
\text { teeth) }\end{array}$} & \multicolumn{2}{|c|}{ G1-SBMP } & \multicolumn{2}{|c|}{$G 2-G C+D$} & \multicolumn{2}{|c|}{ G3- IB } \\
\hline & & Cold & Pressure & Cold & Pressure & Cold & Pressure \\
\hline & & $1(1)$ & $3(1)$ & $4(1)$ & $4(1)$ & $6(1)$ & $6(1)$ \\
\hline & & $0(6)$ & $2(1)$ & $1(1)$ & $1(1)$ & $4(2)$ & $4(2)$ \\
\hline & & & $0(5)$ & $0(5)$ & $0(5)$ & $3(1)$ & $3(1)$ \\
\hline & & & & & & $2(1)$ & $2(1)$ \\
\hline & & & & & & $0(2)$ & $0(2)$ \\
\hline
\end{tabular}

* According to visual analogue scale (0-10).

results compared with those registered at $\mathrm{T}_{0}, \mathrm{~T}_{1}$ and $\mathrm{T}_{2}$. No differences were detected comparing the four evaluation periods $(\mathrm{P}>0.05)$ for the three adhesive systems. Important to mention that these six patients were sent to the clinical facilities to be evaluated and if necessary to have their restorations replaced.

\section{Discussion}

The adhesive systems selected for this study present different approaches and compositions. These differences led to specific protocols ${ }^{8,9,15}$ as described in materials and methods. These differences also could lead to different levels of POS.

The distribution of the sample among patients, tooth type (molars or premolars) and tooth condition (previously restored or decayed) does not seem to interfere in the final results even considering the higher number of molars and previously restored teeth. The presence of the three adhesive systems in each patient and a very low POS rate could strengthen this affirmation.

In the present study, the POS after cold and pressure stimuli was evaluated with VAS, which is widely used in human clinical ${ }^{17}$ and psychological research to assess subjective states. ${ }^{18}$ The restorations were blindly evaluated by one previously trained examiner. Before pressure and cold tests, some non-involved teeth were tested to inform the patient his or her sensitivity levels. Consequently, each patient was instructed to classify the sensitivity of the restored teeth (according to VAS) beyond the normal pattern. For that reason, as the patients knew the ordinary sensation to cold and pressure stimuli, they were instructed to consider it 0 (zero) and only register the POS beyond this point. Doing so, we believe to have voided the individual differences in tolerating pain and detected the real POS caused by the restorative procedure.

The etch-and-rinse systems used in this study increase dentin permeability. Hence, anything that can increase the fluid flow movement should increase dentin sensitivity. ${ }^{6,19}$ However, both etch-and-rinse systems have specific mechanisms that work against POS. SBMP has an hydrophobic coat ( $3^{\text {rd }}$ step) and the GC+D Glutaraldehyde in its formula. The all-inone self-etch adhesive, IB, does not have an acid conditioner. Instead, a blend of monomers (UDMA and 4-META) in a high amount of solvents (acetone and water) are present. Glutaraldehyde is another component added to its formula to act as desensitizer.

POS was only present in two teeth restored with SBMP / Filtek Supreme detected at $\mathrm{T}_{1}$. According to the patient's report (score 1) and the results of cold and pressure tests (score 2 and 3 ) this modification in sensitivity may be considered mild. The increase in dentin permeability provoked by acid-etching associated to a possible adhesive defect would be one of the explanations for this event. However, additional reasons may also be responsible for the increase in sensitivity, such as those motivated by normal operatory procedures. After $T_{2}$, no restored teeth showed sensitivity different from others considered as normal. Our results, consequently, can be compared to those obtained by Casselli and Martins ${ }^{3}$ (2006) and Perdigão et al. ${ }^{9}$ (2003), despite the differences in the evaluation approach. In these mentioned studies, the results of POS in latter periods were not different compared with the initial sensitivity observed, results also found in our data.

In this study class I cavity was chosen due to the adverse C-Factor. ${ }^{7}$ Briso et al. ${ }^{4}$ (2007) detected POS only in $5 \%$ of 143 class I restorations. When class 
II $\mathrm{MO} / \mathrm{DO}$ was evaluated, $15 \%$ of the restorations presented POS, while for MOD, $26 \%$ experienced such an event. This increased POS may be explained in that, although cavity configuration (C-factor) of class II preparations is more favorable to dissipating polymerization stresses, $7,10,11$ the destruction of dental structure seems to have been a determinant factor in the occurrence of POS. The cusp deflection/expansion may explain such events. During an adhesive procedure a sequence of cuspal displacement takes place. Drying produces rapid cuspal contraction. Bonding causes slight cuspal expansion, whereas light curing of resin induces gradual but extensive cuspal contraction, which persists following light curing. The large, rapid fluid movement and cuspal displacement during restoration, and the prolonged outward fluid flow post-curing have implications for post-operative sensitivity. ${ }^{20}$

Besides the destruction of some important parts of the tooth anatomy, such as marginal ridges, one aspect that may significantly affect POS is the cavity depth. Unemori et al. ${ }^{2}$ (2004) determined the incidence in POS according to adhesive type, cavity depth and the presence of bases or liners. The overall POS was higher for the etch-and-rinse adhesive systems, while in deep and medium cavities, when self-etching adhesive was used, the sensitivity was significantly lower. Auschill et al. ${ }^{21}$ (2009) evaluated the appearance of POS after adhesive treatments and the stimuli that may have caused it. Cavity depth was the only factor to have influence on the appearance of POS: deep caries lesions showed four times the risk to present the discomfort, while cavities with pulp exposure had a 14 times higher risk. Based on these comments and the results of the present study one may assume that cavity depth plays a more significant role on POS than the adhesive type. This point was somehow commented upon in the study of Perdigão et al. ${ }^{9}$ (2003) which states: "The choice of dentin adhesive (etch-and-rinse or self-etching) did not result in any significant difference in postoperative sensitivity. The clinical technique, therefore, may be more relevant for the development of immediate POS than is the type of adhesive itself."

The 33-month results were analyzed despite the reduced sample size. Painful symptoms are not a common reason for composite resin restoration replacements. According to a clinical survey ${ }^{22}$ only $8.5 \%$ of the composite restorations have to be replaced when sensitivity was the main complaint. Although this critical point mentioned did not allow us to affirm consistently, it was reasonable to assume that one bottle simplified self-etching IB system could be responsible for the higher sensitivity exhibited after several months of clinical use. Clinical problems related to low bond strength and mechanical properties may show up after some months or years. It has been claimed ${ }^{13}$ that oversimplification of the adhesive clinical application may threaten to some extent the medium- and long-term clinical behavior of restorations. De Munk et al. ${ }^{15}$ (2005) mention that despite the limited amount of in vitro data, it can be concluded that the bonds obtained by mild two-step self-etch adhesives seem quite durable, in contrast to all-in-one, such as IB adhesives, that produce less durable bonds in vivo. Another aspect of the IB system is related to its formula. HEMA, normally found in the composition of numerous adhesive systems, is not present in the IB formulation. Since HEMA-free one-step adhesives are complex blends of hydrophilic/hydrophobic ingredients, water and high amount of solvent, they are prone to phase separation, which accounts partially for their lower bonding effectiveness and mechanical properties. $^{5,23,24}$ Besides, the presence of glutaraldehyde does not seem to negatively affect the bond strength and durability of self-etching adhesives, ${ }^{25}$ however, aspects related to the chemical complexity of some adhesives, specially the all-in-one type, may contribute to the presence of some clinical failures.

\section{Conclusion}

The null hypothesis stating that all adhesives perform equally well in class I restorations concerning postoperative sensitivity must be accepted with regard to 48-hour and 7-day periods. However, larger and deeper cavities and longer observation periods must be included in clinical protocols.

\section{Acknowledgements}

This study was supported by CNPq (Ministry of Science and Technology). 


\section{References}

1. Brännström M, Astron A. A study on the mechanism of pain elicited from the dentin. J Dent Res. 1964 Jul-Aug;43(4):61925.

2. Unemori M, Matsuya Y, Akashi A, Goto Y, Akamine A. Selfetching adhesive and post-operative sensitivity. Am J Dent. 2004 Jun;17(3):191-5.

3. Casselli DSM, Martins LRM Postoperative sensitivity in class I composite resin restoration in vivo. J Adhes Dent. 2006;8(1):53-58.

4. Briso ALF, Mestrener SR, Delício G, Sundfeld RH, BedranRusso AK, de Alexandre RS, et al. Clinical assessment of postoperative sensitivity in posterior composite restorations. Oper Dent. 2007 Set-Oct;32(5):421-426.

5. Van Landuyt KL, Peumans M, Fieuws S, De Munk J, Cardoso $\mathrm{MV}$, Ermis RB, et al. A randomized controlled clinical trial of HEMA-free all-in-one adhesive in non-carious cervical lesion at 1 year. J Dent. 2008 Oct;36(10):847-55.

6. Pashley DH. Dentin permeability and its hole in the pathobiology of dentin sensitivity. Arch Oral Biol. 1994;39 Suppl 1:73-80.

7. Carvalho RM, Perreira JC, Yoshiama M, Pashley DH. A review of polimerization contraction: the influence of stress development versus stress relief. Oper Dent. 1996 JanFeb;21(1):17-24.

8. Van Meerbeek B, De Munck J, Yoshida Y, Inoue S, Vargas M, Vijay Y. Adhesion to enamel and dentin: current status and future challanges. Oper Dent. 2003 May-Jun;28(3):215-35.

9. Perdigão J, Geraldeli S, Hodges JS. Total-etch versus self-etch adhesive: effect on postoperative sensitivity. J Am Dent Assoc. 2003 Dec;134(12):1621-9.

10. Tantbirojn D, Versluis A, Pintado MR, DeLong R, Douglas W. Tooth deformation patterns in molars after composite restoration. Dent Mater. 2004 Jul;20(6):535-42.

11. Lee M, Cho B, Son H, Um C, Lee I. Influence of cavity dimension and restoration methods on cusp deflection of premolars in composite restoration. Dent Mater. 2007 Mar;23(3):28895.

12. Tay FR, Pashley DH, Suh B, Carvalho RM, Itthagarun A. Single-step adhesives are permeable membranes. J Dent. 2002 Sep-Nov;30(7-8):371-82.

13. Tay FR, Pashley DH, Suh BI, Hiraishi N, Yiu CK. Buonocore memorial lecture. Water treeing in simplified dentin adhesivesdéjà vu? Oper Dent. 2005 Sept-Out;30(5):561-79.
14. Yui CKY, Hiraishi N, Chersoni S, Breschi L, Ferrari M, Prati C, et al. Single bottle adhesives behave as permeable membranes after polymerisation II. Differential permeability reduction with an oxalate desensitizer. J Dent. 2006 Feb;34(2):106-16.

15. De Munk J, Van Landuyt K, Peumans M, Poitevin A, Lambrechts P, Braem M, et al. A critical review of the durability adhesion to tooth tissue: methods and results. J Dent Res. $2005 \mathrm{Feb} ; 84(2): 118-32$.

16. Turkun SL. Clinical evaluation of a self-etching and one-bottle adhesive system at two years. J Dent. 2003 Nov;31(8):52734.

17. Aranha ACC, Pimenta LAF, Marchi GM. Clinical evaluation of dessensitizing treatments for cervical dentin hypersensitivity. Braz Oral Res. 2009 Jul-Sep;23(3):333-9.

18. Ozen T, Orhan K, Avsever H, Tunka YM, Ulker AE, Akyol M. Dentin Hypersensitivity: a randomized clinical comparison of three different agents in a short-term treatment period. Oper Dent. 2009 Jul-Aug;34(4):392-8.

19. Pashley DH. Dentin permeability and dentin sensitivity. Proc Finn Dent Soc. 1992;88(1):31-7.

20. Ratih DN, Palamara JEA, Messer HH. Dentinal fluid flow and cuspal displacement in response to resin composite restorative procedures. Dent Mater. 2007 Nov;23(11):1405-11.

21. Auschill TM, Koch CA, Wolkewitz M, Hellwing E, Arweiler NB. Occurrence and causing stimuli of postoperative sensitivity in composite restorations. Oper Dent. 2009 JanFeb;34(1):3-10.

22. Parpaiola AR, Guimarães PS, França FMG, Basting RT. Small cross-sectional survey of composite restoration attributes associated with choices for replacement. Braz Oral Res. 2009 Jul-Sep;23(3):346-51.

23. Shirai K, De Munk J, Yoshida Y, Inoue S, Lambrechts P, Suzuki $\mathrm{K}$, et al. Effect of cavity configuration and aging on the bonding effectiveness of six adhesive to dentin. Dent Mater. 2005 Feb;21(2):110-24.

24. Van Landuyt KL, Snawaert J, Peumans M, De Munk J, Lambrechts P, Van Meerbeek B. The role of HEMA in one step self-etch adhesives. Dent Mater. 2008 Oct;24(10):1412-19.

25. Omae M, Inoue M, Itota T, Finger W,Inoue M, Tanaka K, et al. Effect of a desensitizing agent containing glutaraldehyde and HEMA on the bond strength to Er:YAG laser-irradiated dentine. J Dent. 2007 May;35(5):398-402. 